\title{
استراتيجية تعليم اللغة العربية بالألعاب اللغوية
}

Akhmad Zaifuddin, Mohammad Zainal Hamdy

IAI Al-Khairat Pamekasan, Sekolah Tinggi Agama Islam Darul Ulum

Banyuanyar Pamekasan

syaifulelhamida@gmail.com, Hamdyhernandez14@gmail.com

\section{ملخص البحث}

كما عرفنا أن تعليم اللغة العربية قد نشر بإندونيسيا، إما في المؤسسات الرسمية أم

غير الرسمية، وإما في المدارس أم في المعاهد أم في الجامعات. ولكن من الآسف، أن تعليم اللغة العربية في بلادنا الآن مازال ولم يزل يعاني مشكلات متعدّدة. ومن تلك المشكلات الخفاض دافعية الطلبة في عملية التعليم. وانخفاض الدافعية وجده الكاتب عند الطلبة في المدارس والجامعات. ويحللها الكاتب فوجدها أن مشكلة دافعية الطلبة تتركز كثيرة في الأمور الأربعة، وهي حول الدفاع والاحتياج في الدراسة، الرجاء والأمل للمستقبل، والبيئة الدراسية. ثم استنتج الكاتب أن أكثر الطلبة ضعفاء في هذه الأمور الأربعة. فلهذا، جرّب الكاتب أن يقدّم استراتيجية تعليم اللغة العربية بالألعاب اللغوية لأن لعب اللغوية دورا هاما في إثارة الدافعية والمحافظة عليها. الكلمات المفتاحية: استراتيجية، تعليم اللغة العربية، الألعاب اللغوية 
كما عرفنا أن التعليم عو عملية تربوية يحدث فيها تفاعل بين المعلّم والمتعلم روحا وجسدا حيث يمكن لمما نقل المعلومات. ولايقتصر هدف التعليم على نقل المعلومات فحسب ركب وإنما يرجى منه أن يحدث تغير في سلوك المتعلم، أي تغيّر من الشرّ إلى الخير أو من النقص إلى الكمال أو من درجة الجودة إلى درجة الامتياز . وبالموجز أن التعليم الذي يقوم به المعلم والمتعلم يلزم أن يحصّل ترقية وينتج تطوّرا ذا معنى لدى المعلم والمتعلم. ومن ثمّ يجب على المعلم أن يهتمّ بعوامل تعيّن نجاح التعليم. فالعوامل التي تعيّن نجاح

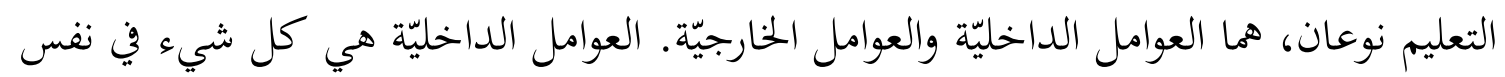
المعلم والمتعلم يؤثّر على عملية التعليم مثل الدافعيّة والميول والملكة العقلية والملكة العاطفيّة وغيرها. وأما العوامل الخارجيّة فهي كل شيء يأتي من خارج المعلّم والمتعلّم ويؤثّر على عملية التعليم مثل الأدوات التعليميةوالبيئة والوسائل التعليمية والطرق التعليمية وغيرها. فإذن، التعليم الجيد لابد من مراعاة العوامل الداخليّة والعوامل الخارجيّة.

وفي مجال تعليم اللغة، إن اللغة العربية لما منصب أعلى في العالم حيث تصير من إحدى اللغات الرسميّة لدى هيئة الأمم المتّحدة. وليست هي لغة دينية قط بل لغة لجميع بجالات الأعمال كالإقتصاد والسياسة والاجتماعية والحضارة والثقافة وغيرها. وليست هي لغة للعبادة فحسب وإنما لغة للإتصال أيضا. لذا، تعلم اللغة العربية في المدارس والمعاهد والجامعات من المرحلة الإبتدائية إلى مرحلة الجامعة، وتعلم أيضا في المؤسسات الرميّة أم المؤسسات غير الرسميّة، وتعلم أيضا في المؤسسات الإسلامية أم المؤسسات العامّة. فبالطبع هذه ظاهرة جيدة تدل على أن اللغة العربية ظلّت وتظلّ تنال إنجازا عاليا من جميع القبل. وهذه فرصة جميلة لدينا كمعلمي اللغة العربية لتعليمها ولتطويرها ولتجديدها.

ولكن من الآسف، أن تعليم اللغة العربية في بلادنا الآن مازال ولم يزل يعاني مشكلات متعدّدة معقّدة حتى لمُ يصل إلى الهدف الذي خطّطته الجامعة ولم تحصل على الغاية التي 
وضعتها الحكومة وكذلك لم تستوف الرجاء الذي يودّعه الآباء والأمّهات عند تسجيل أبنائهم

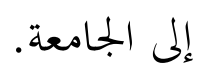

ومن ملاحظة الكاتب في الميدان، أن تراوح تلك المشكلات بين المدرّسين والدّارسين.

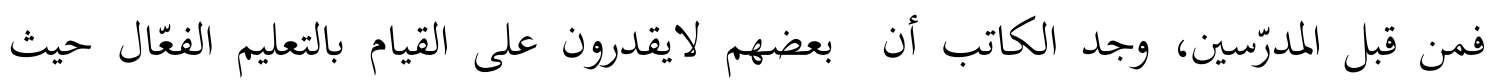
لايختارون المواد الدراسية الجذابة التي تناسب عقولم وتنبعث بها ميولم، وهم يعجزون من استخدام الطريقة التعليمية حتى لاتتناسب الطريقة والمواد المدروسة ولم تكن مقبولة عند الطلبة. بل لايقدرون على أن يتطوّروها في شكل استراتيجيات متنوعة تنهض دافعية الطلبة عند

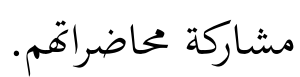
ولذا، يودّ الكاتب أن يقدّم استراتيجية تعليم اللغة العربية بالألعاب اللغوية. وقد توصلت كثير من البحوث أن استخدام اللعبة اللغوية يؤدّي إلى ترقية فعالية عملية التعليم والتعلم كما يؤدّي إلى ترقية مدى استيعاب الدارسين للمواد الدراسية.

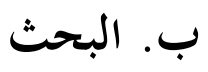

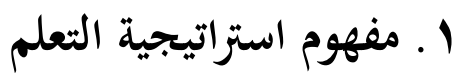

استراتيجية التعلم هي أداء خاصة يقوم بها المتعلم ليجعل عملية التعلم أسهل وأسرع إقناعا وأكثر ذاتية في التوجيه، وأكثر فعالية وأكثر قابلية للتطبيق في مواقف جديدة.' وأكدّه

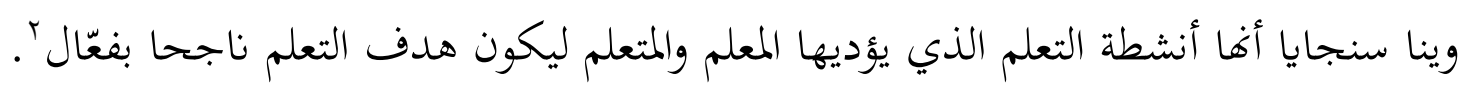
يعرف منى إبراهيم اللبودي أن تنمية فنيات الكلام أو الحوار تستلزم إعداد برنامج مناسب ومخطط لتحقيق أهداف محددة مستمدة من أسس الحوار الفعال ومن أهداف تعليم

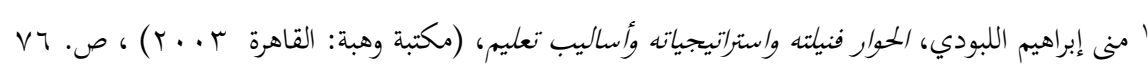

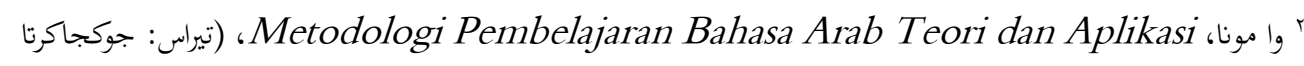


اللغة العربية في مرحلة دراسية معينة، بجيث يشتمل البرنامج على صياغة الأهداف واختيار وتنظيم المحتوى وتحديد طرق التدريس والأنشطة والوسائل التعليمية وأساليب التقويم المناسبة.

وعرف سهير محمد سلامة شاش الإستراتيجية التعلم بأهما خطوات إجرائية منتظمة

ومتسلسلة بحيث تكون شاملة ومرنة ومراعية لطبيعة المتعلمين، والتي تمثل الواقع الحقيقي لما يجدث داخل قاعة الدراسة من استعلال لإمكانات متاحة، لتحقيق مخرجات تعليمية مرغوب فيها.بجموعة تحركات المعلم داخل قاعة الدراسة التي تحدث بشكل منتظم ومتسلسل تمدف إلى تحقيق الأهداف التعليمية.r

وتسمى استراتيجية التعليم بتقنية التعليم وهي التفعيل من الطريقة. لذا، وتقنية التعليم التصميم والتنظيم والتخطيط والوسيلة في الممارسة سوف لعبت في عملية التعليم والتعلّم بالفصل لأجل تحقيق هدف التعلم.؛

ويقال التعليم بجهد جعل نظام البيئة الذي يتكون على العناصر الآتي:

$$
\text { ( ) ( ) ) المدرّس ) مدف التعليم }
$$

r سهير محمد سلامة شاش، اللعبة وتنمية اللغة لدى الأطفال ذوي الإعاقة العقلية الطبعة الثالثة، (القاهرة: مكتبة الأنجلو المصرية

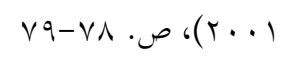

${ }^{4}$ M. Abdul Hamid, dkk, Pembelajaran Bahasa Arab (Malang: UIN-Maliki Press 2008), hlm: 4

${ }^{5}$ Syaiful mustofa, Strategi Pembelajaran Bahasa Arab Inovatif( Malang : UIN-

Maliki Press 2011), hlm: 9 


\section{Y . استراتيجية تعليم اللغة العربية}

أن استراتيجيات تعلم اللغة تعرف الطلاب كيف يتعلمون، وتساعدهم على الإستفادة بأقصى حد ممكن من الخبرات التعليمية التي يمرون بها داخل المدرسة وخارجها. وهي قابلة للتعليم، ويتطلب تعلمها دمج التدريب عليها مع المهام الأخرى التي يشتمل عليها برنامج تعلم اللغة فهي لايتم تعليمها بفعالية بعيدا عن محتوى لغوي محدد.

ومن الإستراتيجيات المناسبة لعملية التعليم والتعلم، ما يلي:؟

$$
\text { ( ) فهم عملية تعلم اللغة }
$$

r) تحديد الأهداف العامة والخاصة

r) فهم الغرض من المهمة اللغوية

§) التخطيط للمهمة اللغوية

ه) البحث عن فرص للممارسة العلمية

7) المراجعة الذاتية

V) التقويم الذاتي (V)

^) استراتيجية لخفض مستوى القلق

$$
\text { 9) (1) استخدام العبارات المشجعة }
$$

" سيف المصطفى، اللغة العربية ومشكلات تعليمها (مالانق: مطبعة جامعة مولانا مالك إبراهيم الإسلامية الحكومية بمالانق

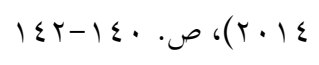




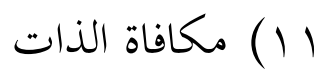

$$
\text { r (1) طرح الأسئلة }
$$

r (1) - (1) التعاون مع الآخرين

ع ( ) مراعاة مشاعر وأفكار الآخرين.

وإن هناك ثمانية خصائص للتعليم والتعلم على أساس الألعاب اللغوية وهي:

() أن يكون الطالب في العملية التعليمية يربط بينه والآخر ارتباطا ذا معنى أي أنه يمكن أن ينظم كل طالب كالدارس الناشط في تنمية ميوله ورغباته فرديا، أو كالعامل وحده أو

كالعامل مع غيره، أو كالدارس الذي يتعلم بواسطة العمل learning by doing r) أن يكون الطالب لعمل الأنشطة الهامة. r) أن يكون الطالب تنظيم تعلمه بنفسه. ع) أن يكون الطالب متعاونا مع غيره من الطلاب في العملية التعليميه. ه) ان يفكر الطالب تفكيرا انتقاديا وإبداعيا. ج) يعتبر التعليم تربية لشخصية الطلاب. V) الهدف الرئيس في التعلم هو تحقيق المستوى العالي high standard أي أن يعرف رئ الطالب المستوى العالي في التعليم ويريد أن يصل إلى درجة متتازة excellence. لذا، يجب أن يحدد المعلم الأهداف التعليمية وأن يشجع الطالب لنيل هذه الدرجة. ᄉ) ( م أن يستعمل التقويم الأصيل. مكونات استراتيجيات التعليم والتعلم ( ) (الأهداف التعليمية Y رمضان محمد القذافي، رعاية الموهوبين والمبدعين (الإسكندارية: المكتب الجامعي الحديث، ب99 199 م)، ص. ع 
r) التحركات التي يقوم بها المعلم وينظمها ليسير وفقها في تدريسه. r) الأمثلة، والتدريبات والمسائل والوسائل المستخدمة لتحقيق الأهداف. ع) السياق التعليمي والتنظيم الصفي للدرس ه) استجابات الطلبة بمختلف مستوياقم والنابتحة عن المثيرات التي ينظمها المعلم ويخطط لها. r. عناصير استراتيجية التعليم

هناك خمسة عناصر لابد من إبرازها في كل استراتيجية وتلك العناصر كمثل الآتية: ( ) الأنشطة قبل التعليمية (preinstructional activities) (Y) تقديم المعلومات (information presentation) r) (student participation) مشاركة الدارس ( ) ( الإختبارات (testing)

(follow through) المتابعة (2) ع ـ تعليم اللغة العربية

أهمية تعليم اللغة العربية تتمثل في التدريب على المهارات الخاصة بالاتصال اللغوي متمثلة في المحادثة والاستماع والقراءة والكتابة حتى تتم عملية الإتصال اللغوي على أحسن أداء. ويتجه نفر من المربّين إلى تعليم اللغة العربية على أها وحدة متكاملة من غير أن بجزأ إلى

$$
\text { فروع، وفي حين يرى آخر أن تعليم اللغة العربية ينبغي أن يتمّ من خلال فروعها. }
$$

فروع اللغة كثيرة، ولها نظريتان في تعليمه، هما نظرية الوحدة ونظرية الفروع. وسيأتي البيان

$$
\begin{aligned}
& \text { عن هذا الأمر فيما يلي: } \\
& \text { ( ) نظرية الوحدة }
\end{aligned}
$$


ترى هذه النظريّة أن اللغة وحدة مترابطة متماسكة، وليست فروعا مفرّة مختلفة، والأسلوب المتّبع في تعليم اللغة بهذه النظرية أن يتخذ الموضوع أو النص محورا تدور حوله جميع الدرسات اللغوية. فيكون هو موضوع القراءة والتعبير والتطبيق النحويّ والحفظ والإملاء وغير ذلك. وقد جرى القدماء على استعمال هذه النظرية في التعليم، فكان النص محوراكل شيء في الدراسات اللغوية والأدبية.^ r) نظرية الفروع

المراد بنظرية الفروع عند الركابيج وإبراهيم '، هي تقسيم اللغة فروعا، لكلّ فرع منهجه وكتبه وحصصه، مثل المطالعة والمحفوظات والتعبير والقواعد والإملاء والأدب والبلاغة.

\section{هـ أسس تعليم اللغة العربية}

تعليم اللغة العربية يعتمد على الأسس الخمسة، وهي أولويات التقديم، التدرج، عنصر التشويق، الدقة في الأصوات والتراكيب والمعاني، والصلابة والمتابة.

\section{4. أهداف تعليم اللغة العربية}

يمكن تلخيص أهداف تعليم اللغة العربية لغير الناطقين بها في النقاط الآتية:" أن يمارس الطالب اللغة العربية بالطريقة التي يمارس بها الناطقون بهذه اللغة أو

$$
\text { بصورة تقرب من ذلك. }
$$

اكتساب الطالب القدرة على استعمال اللغة استعمالا ناجحا في الإتصال بغيره

$$
\text { عن طريق التحدث والكتابة والإستماع والقراءة. }
$$

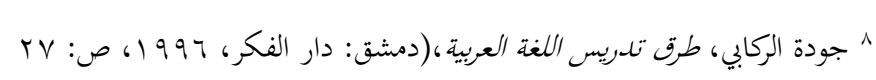

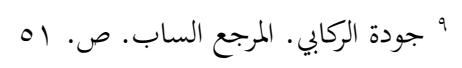

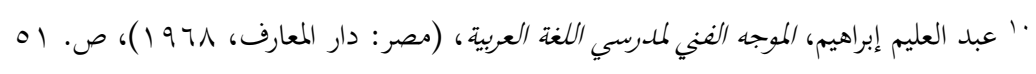

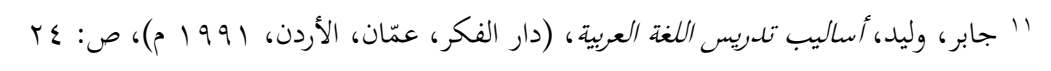


تدريب الطالب على القراءة الصامتة بسرعة مناسبة مع فهم الحكم بالقدر

$$
\text { الذي يسمح له نموه العقلي واللغوي في هذه المرحلة . }
$$

تدريب الطالب على الاستماع وتركيز الانتباه إلى ما يسمعه، وعلى فهمه فهما

$$
\text { مناسبا واستخلاص الأفكار الجوهرية منه. }
$$

تنمية قدرة الطالب على النطق الصحيح للغة والتحدث مع الناطقين بالعبية حديثا معبرا عن المعنى سليما في الأداء.

$$
\text { تنمية ميل الطالب إلى القراءة الحرة الواسعة في أوقات الفراغ. }
$$

تنمية قدرة الطالب على التعبير بمختلف اساليب التعبير وأنواعه مع العناية

بوضوح الأفكار ودقتها وصحتها وتنظيمها.

تنمية قدرة الطالب على الكتابة الصحيحة الواضحة التي تقراء بسهولة ويسر.

الوصول بالطالب إلى الإحاطة بالوقاعد الأساسية في اللغة والإملاء وتدريبه

$$
\text { عليها تدريبا كافيا. }
$$

(·) أن يعرف الطالب خصائص اللغة العربية وما يميزها عن غيرها من اللغات

$$
\text { أصوات مفردات وتراكيب ومفاهيم. }
$$

(11) تنمية قدرة الطالب على التذوق الأدبي من خلال دراسة النصوص الأدبية. (r) (I ا تنمية قدرة الطالب على معرفة النصوص القرآنية والحديثية والمعارف الإسلامية

$$
\text { المكتوبة بالعربية. }
$$

(r (I أن ينشأ الطالب متشعبا بروح الإسلام معتزا به متزودا بزاد القرآن الكريم. فاهما للحديث الشريف متعظا بمكمه. ويتعرف على أمثلة من الخلق الإسلامي 
( (1) أن يتعرف الطالب على الثقافة العربية الإسلامية وأن يلمَّ بخصائص الإنسان العربي والبيئة التي يعيش فيها والمجتمع الذي يتعامل معه. (10) تمكين الطالب من استعمال المعاجم والانتفاع بالمكتبة والفهارس. (7 ( ) تنمية قدرة الطالب على أداء شعائر الدين الإسلامي بشكل دقيق.

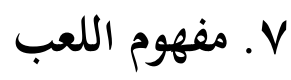

( ) ما هو اللعب؟

اللعب هو نشاط حرّ وموجّه يكون على شكل حركة أوعمل، يمارس فرديا أو جماعيّا، ويستغلّ طاقة الجسم العقلية والحركيّة، ويمتاز بالسرعة والحنفة لارتباطه بالدوافع الداخلية، ولا يتعب صاحبه، وبه يتمثّل الفرد المعلومات ويصبح جزءا من حياته، ولا يهدف إلا إلى

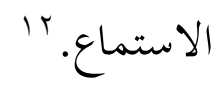
r) (r) - (بل اللعب للطفل فحسب؟ اللعب نوع من أنواع الوسائل التعليمية ونشاط مهمّ من أنشطة التعليم الإتصاليّ وتحقق الألعاب قدرا كبيرا من الواقعية، التي لابد منها عند الإتصال، وتستخدم الألعاب اللغوية مع

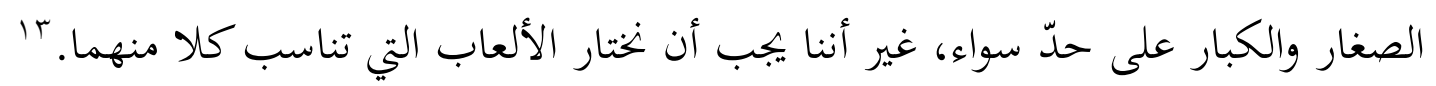

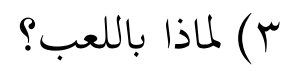
يعدّ اللعب من أهم الأنشطة التي يمارسها الفرد فتستهويه ومن ثم تثير تفكيره وتوسّع خياله، ويسهم اللعب بدور حيويّ في تكوين شخصية الفرد بأبعادها وسماتا المختلفة، وهو وسيط تربويّ مهم يعمل على تعليمه ونمّه ويشبع احتياجاته، ويكشف أمامه أبعاد العلاقات

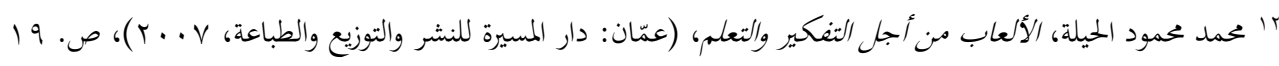

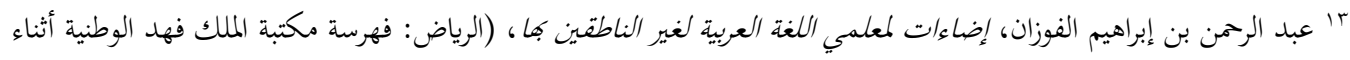

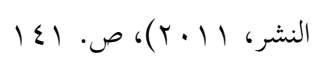


الاجتماعية والتفاعليّة القائمة بين الناس، ويعدّ اللعب عامّة مدخلا أسسيّا لنموّ الفرد من الجوانب العقليّة والجسميّة والاجتماعيّة والأخلاقيّة والانفعاليّة والمهاريّة واللغويّة. ويّّصف اللعب

بعدّة سمات يمكن إجمالها في الآتي:

اللعب نشاط لا إجبار فيه وغير ملزم للمشاركين فيه، وقد يكون بتوجيه من لو لر

\section{الكبار أو بغير توجيه.}

تعدّ المتعة والسرور جزءا رئيسا وهدفا يمقّقه اللاعبون من خلال اللعب، وغالبا

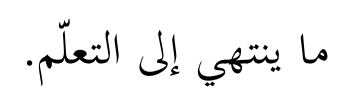

من خلال اللعب يمكننا استغلال الطاقة الذهنيّة والحركيّة للاعب في آن واحد.

يرتبط اللعب بالدوافع الداخليّة الذاتيّة، حيث أنه يتطلّب السرعة والخفّة

$$
\text { والانتباه وتفتح الذهن. }
$$

اللعب مطلب أساسيّ لنموّ الفرد ولتلبية احتياجاته المتطوّرة ولتعليمه التفكير.

اللعب عمليّة تمثّل، أي أن الفرد يتعلم باللعب، وحتى يكون اللعب فِّالا لابدّ

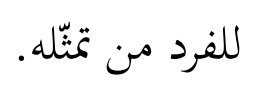

اللعب مطلب أساسيّ لإثارة التفكير، وتوسيع مجال التخيّلات، وبناء

$$
\begin{aligned}
& \text { التصوّرات الذهنيّة للأشياء. } \\
& \text { ع أشكال وأنواع اللعب } \\
& \text { وقد صنّف الهنداوي في الآتي:10 }
\end{aligned}
$$

الألعاب التلقائية: تمثل الأشكال الأوّلية للعب، وهو في معظمه انفراديّا ولايتمّ ضمن مجموعات، ويلعب الفرد فيه كلّما رغب، ويتوقّف عنه حينما لايتمّ به، ومعظم ألعاب هذا النوع هي استقصائيّة واستكشافيّة.

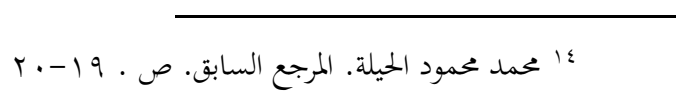

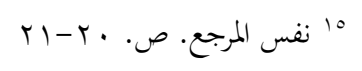


ألعاب تثثيل الأدوار: ويعتمد هذا النوع من الألعاب على خيال الأفراد الواسع ومقدراقم الإبداعيّة. وينشأ هذا النموذج من اللعب استجابة لانطباعات انفعاليّة قويّة يتأثر فيها الفرد بنموذج من الحياة في الوسيط المخيط به.

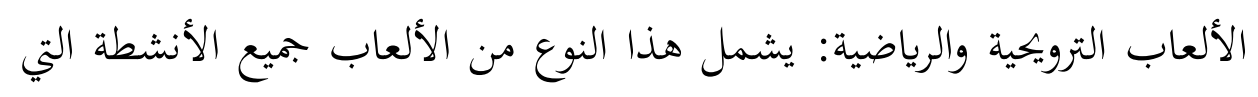
يقوم بما الفرد والتي تنتقل من جيل إلى جيل.

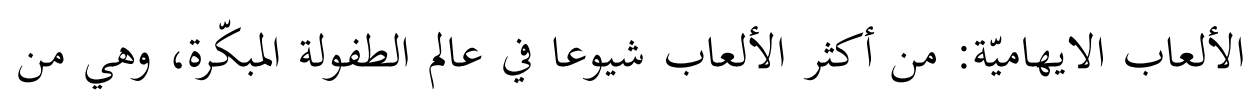

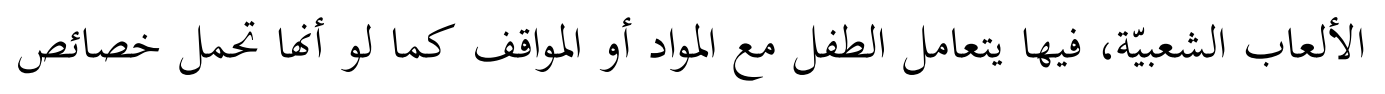

$$
\text { أكثر مما تتّصف به في الواقع. }
$$

الألعاب الفنّيّة: هي إحدى أنواع الألعاب التركيبيّة، وتعدّ من الأنشطة الفنّيّة

التعبيرّة التي تنبع من الوجدان والتذوّق الجماليّ ومنها الرسم بالموادّ المختلفة.

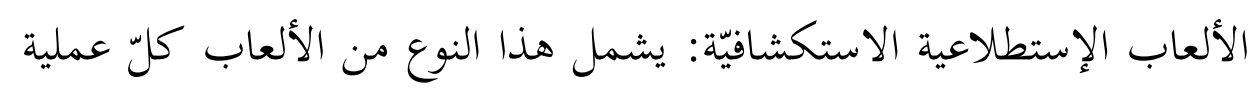

يقوم هما الفرد لمعرفة المكونات التركيبّة لشيء ما وكيف يعمل ذلك الشيء.

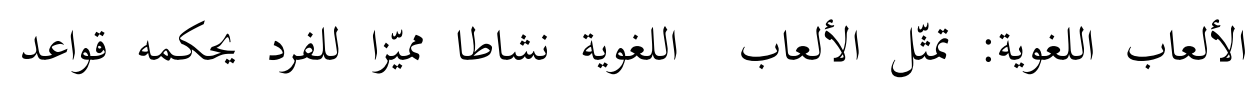

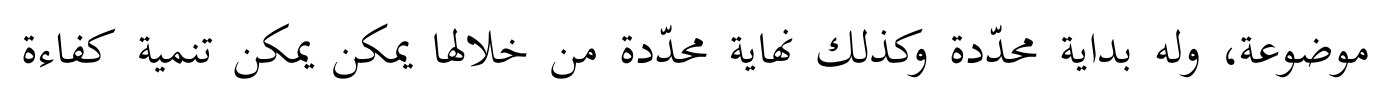
الإتصال اللغويّ بين الأفراد وتدريبهم على الاستخدام الصحيح لكثير من أدوات اللغة

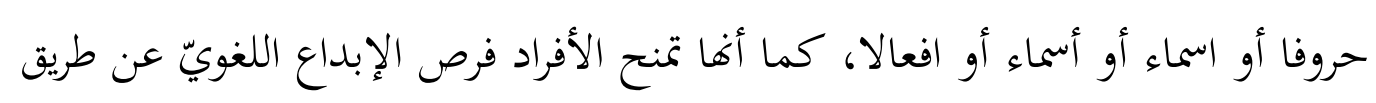
التدريبات الشفويّة الحرّة.

الألعاب الثقافية: من خلال هذه الألعاب يكتسب الفرد معلومات ومعارف الفرف

وخبرات متنوّعة، ويدخل ضمنها الأنشطة القصصيّة المختلفة، كالمطالعة والكتابة.

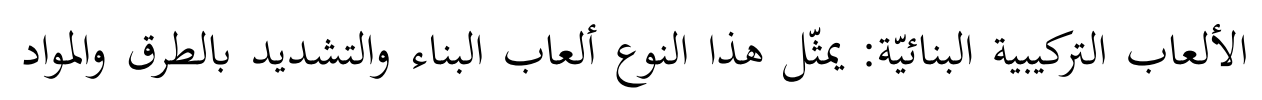

المختلفة. 
(· (1) الألعاب العلاجيّة: وهي أوجه النشاط المختلفة التي توجّه للأفراد الذين يعانون من اضطرابات نفسية مختلفة لتخليصهم متّا يعانون.

\section{^ـ اللعبة اللغوية في ججال تعليم اللغة العربية}

رأى أندري إن تعلم اللغة العربية يعتبر من الجهود الثقيلة والملة بل وقد يجعل الإنسان

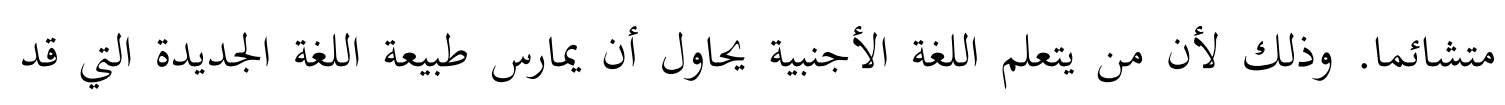
تختلف عن طبيعة لغته الأم في مستويات الأصوات والصرف والنحو والدلالة. وهو ليس بامر سهل إذ أنه يتعلم اللغة الأجنبية بعد ما إعتاد على طبيعة لغته الأم. ومن ثم فإنه من الضروري

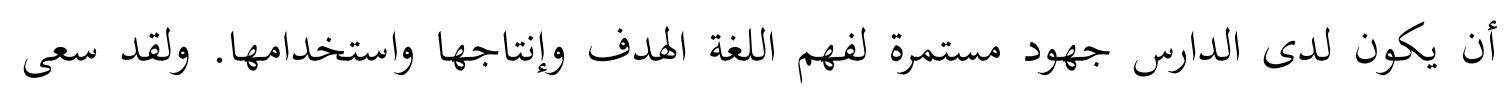
كثير من اللغويين التطبيقيين في البحث عن أساليب تعليم اللغة الأجنبية التي بتنب الدارسين الكسل والخمول والملل والتشاؤم في تعلمهم اللغة الأجنبية. وقد نجحوا في سعيهم واكتشفوا عددا من الأساليب التعليمية الجذابة من بينها اللعبة اللغوية.

ولقد ذكر لي سوكم فوائد استخدام اللعبة اللغوية في تعليم اللغة الأجنبية داخل الفصل

$$
\begin{aligned}
& \text { كما يلي:17 } \\
& \text { ( ) أها تكسر روتينية تعلم اللغة } \\
& \text { r أها تعطي التشجيعات وفي نفس الوقت تعطي التحديات } \\
& \text { ץ) أغها تساعد الدارسين في ترقية جهود التعلم } \\
& \text { ع) أغها تدرب على استخدام اللغة في شتى المهارات } \\
& \text { 0) أها تشجع الدارسين للتعامل والاتصال } \\
& \text { ج) أها تخلق الظروف المفيدة لاستخدام اللغة }
\end{aligned}
$$

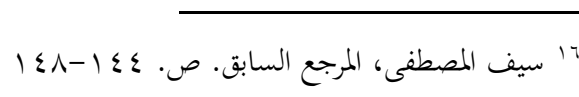


يعرف منى إبراهيم اللبودي هناك كثير من الألعاب اللغوية التي تعتمد على ترقية الحوار

ويتطلب هذا النوع من الألعاب مشاركة بجموعة من الأفراد بحسب قواعد كل لعبة ويكون لكل مشارك دور محدد يؤديه، يمارس في الحياة اليومية بغرض التسلية والمرح ( المناقشة

وتتضمن حوارات ذات هدف محدد ومعروف للمشاركين فيها، بجيث يتبادل المشاركون الرأي حول موضوع أو مشكلة معينة، ويتعاونون في إيياد حل أو إجابة أو قرار

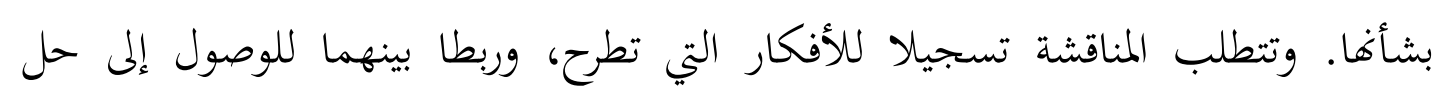

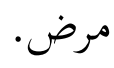
وتأخذ المناقشات أشكالا متعددة من حيث تنظيمها وإدارقا كالآتي:

وينبي استخدامه مع بجموعات صغيرة، ويتطلب رئيسا يدير المناقشة، ويعمل على

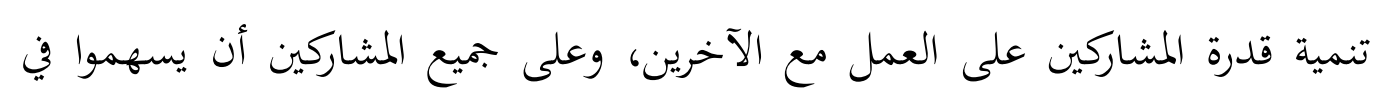
المناقشة، ويجب أن يكون المشاركون على دراية بموضوع المناقشة، إلا أنه يمتاج وقتا كبيرا

$$
\text { نسبيا لممارسته. }
$$

حيث يتم التقديم للموضوع من جانب مجموعة صغيرة من المتحدثين، ويتبعها الأسئلة والمناقشة التي يقوم المنتدى 
يكون التقديم من جانب متحدث واحدا، وتطرح الأسئلة والتعقيبات من قبل الجمهور عقب التقديم ويمكن مشاركة عدد في وقت قصير ويتطلب قدرا من السيطرة لضبط

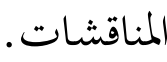

$$
\text { الحلقة الدراسية }
$$

مناقشة جماعية مع أقل قدر من القيادة الرسمية، كما أن يكون المشاركون على قدر كبير من الخبرة بالموضوع. وتكون عملية فقط في حالة وجود جماعة صغيرة وتصلح للمواقف

$$
\text { التي تتطلب إيجاد حلول. }
$$

مناقشة جماعية لموضوع معين، رئيس المناقشة أن يكون ملما بالموضوع، ويتطلب ذلك وقتا طويلا. وتعمل على تنمية مهارة التحليل وحل المشكلات. r) استراتيجية المجموعة الصغيرة

استراتيجية المجموعة الصغيرة هي مجموعة من الطرق التي اقترحها خبراء المناهج وطرق التدريس في محاولة لتطوير الدور التقليدي للمعلم كوعاء للمعرفة، والمصدر الوحيد للسلطة داخل الفصل، ليصبح ميسرا للتعلم ومشاركا لتلاميذه في الأنشطة الصفية من خلال تفويضهم بعض السلطة داخل الفصل. ويتطلب استخدام استراتيجية المناقشة في مجموعات صغيرة هيئة مناخ ملائم في الفصل يسوده الاحترام المتبادل والدعم وتنمية مهارات التصى questioning وتشجيع روح التعاون. وتناسب طرق المجموعات الصغيرة المواقف التي تتطلب زيادة التفاعل اللفظي بين الطلاب والمدرس، والطلاب وبعضهم داخل الفصل وتنمية روح المسؤولية والاستقلالية في التعلم، كما تساعد هذه الطريقة في تحسين مهارة التحدث والنطق 
والتفكير، وتضفى مناخا من التلقائية وممارسة الضبط غير مباشر على أنشطة الطلاب داخل الفصل. كذلك تتيح هذه الطريقة الفرصة للطلاب كي يبحثوا ويقوموا ويتوصلوا لرأي شخصي فهي تعلمهم مهارة التفكير الناقد. وتشمل استراتيجية مناقشات المجموعات الصغيرة على طرق متعددة من أهمها: ( ) أسلوب العصف الذهني brain storm role playing طريقة لعب الأدوار rask group discussion أسلوب مناقشات مجموعات العمل ع ) أسلوب مناقشات اللجان panel discussion

\title{
9 ـ علاقة التعليم باللعب والدافعية
}

وللدافعيّة تأثير كبير في التعليم، فكلّما كان وراء الدارس دافع يستحثه وحافز يشدّه إلى التعلّم كان ذلك أدعى إلى إتمامه وتحقيق الهدف منه، وفقدان الدافع أوضعفه وراء الكثير من

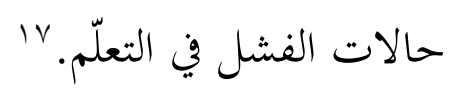

وتدلّ التجارب والعقل السليم على أن الدافع ضروريّ للتعلّم أو للإسراع في التعلّم. فبدون دافع تكون عمليّة التعلمّ بطيئة للغاية ويكون التعرّض للغة مجرّد ضجيج لامعنى له. وكلّما قوي الدافع ودام، قوي الانتباه ودام، وزاد التعلم وأسرع. ^’

وللدافعيّة تأثير كبير في تعلّم اللغة الثانية. ومع اختلاف علماء النفس حول هذا التأثير إلا أفم يجمعون على أنه كلّما كان وراء الدارس دافع يستحثّه، وحافز يشدّه إلى تعلّم شيء ما

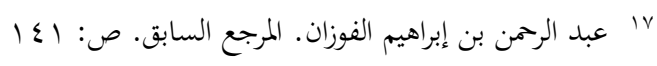

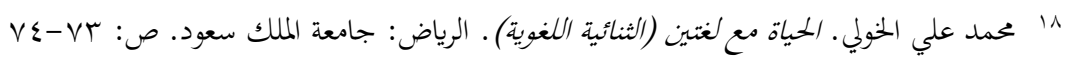


كان ذلك أدعى إلى إتمامه، وتحقيق الهدف منه، خاصة في أشكاله المعقّدة، ومهاراته المتشابكة.

وهل للعب دور في دافعيّة الطلبة؟ نعم إنّ للعب دور في إثارة الدافعية والمحافظة عليها،

$$
\begin{aligned}
& \text { فمن خلال اللعب يمكن للفرد أن يحقّق ما يلي: ‘ } \\
& \text { يساعد الفرد على التفاعل مع البيئة. } \\
& \text { يساعد الفرد على تطوير ذاته. }
\end{aligned}
$$

اللعب وسيلة لاكتساب أنماط السلوك المختلفة.

$$
\text { اللعب وسيلة لتطوير أنماط السلوك. }
$$

تساعد الألعاب الحركيّة التي يمارسها الفرد على تهيئه لتطويره المعري اللاحق.

\section{ج. (المختتمة}

وفقا لنتائج البحث الميدانية أن استراتيجية تعليم اللغة العربية بالألعاب اللغوية عند الطلبة الإندونيسين أحد الأساليب التي يمكن استخدامها لترقية المهارات اللغوية ولإثارة الدافعية لدى الطلبة في تعليم اللغة العربية، واستخدام الألعاب اللغوية يساعد المدرس على القيام بالتعليم المسلّي المفرّح المشوّق والسارّ حتى تشعر الطلبة بالسهولة والحماسة للقيام بعملية التعليم والتعلّم والتدريب ويذهبون إلى الفصل سعداء.

قائمة المصادر والمراجع

$$
\begin{aligned}
& 19 \text { رشدي أمهد طعيمة. المرجع في تعليم اللغة العربية للناطقين بلغات أخرى. جامعة أم القرى معهد اللغة العربية وحدة البحوث }
\end{aligned}
$$

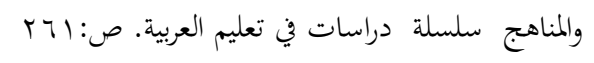

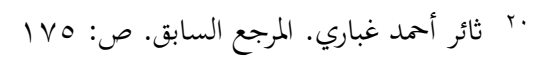


اللبودي، منى إبراهيم ، الحوار فنيلته واستراتيجياته وأماليب تعليم، مكتبة وهبة: القاهرة r...r الركابي، جودة، طرق تلدريس اللغة العربية، دمشق: دار الفكر، 1997

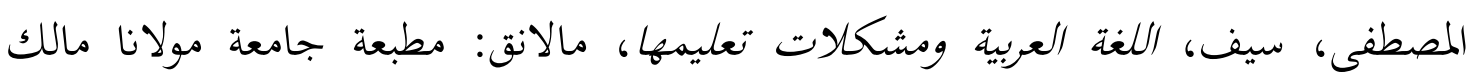

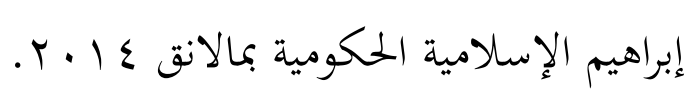

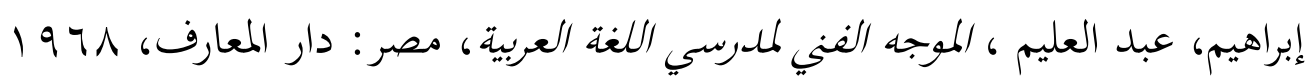

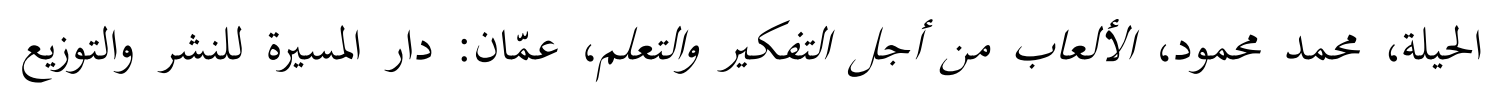

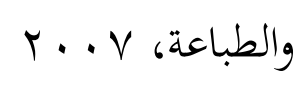

القذافي، رمضان محمد ، رعاية الموهوبين والمبلدعين، الإسكندارية: المكتب الجامعي الحديث،

$$
\text { ? } 1997
$$

الفوزان، عبد الرحمن بن إبراهيم ، إضاءات لمعلمي اللغة العربية لغير الناطقين جما، الرياض:

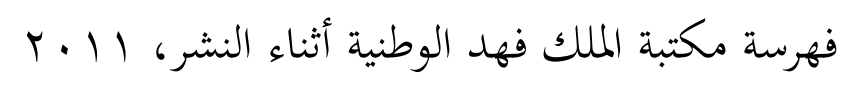

الخولي، محمد علي، الحياة مع لغتين (الثنائية اللغوية). الرياض: جامعة الملك سعود. جابر، وليد، أساليب تلدريس اللغة العربية، دار الفكر، عمّان، الأردن، 1991 م م سلامة شاش، سهير محمد، اللعبة وتنمية اللغة لدى الأطفال ذوي الإعاقة العقلية الطبعة

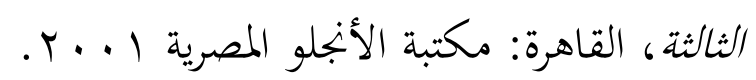

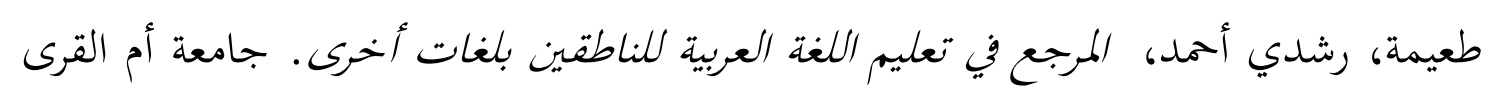
معهد اللغة العربية وحدة البحوث والمناهج سلسلة دراسات في تعليم العربية. وامونا، Metodologi Pembelajaran Bahasa Arab Teori dan Aplikasi، تيراس: جوكجاكرتا $r \cdot 11$

Mustofa, Syaiful, Strategi Pembelajaran Bahasa Arab Inovatif, UIN-Maliki Press, Malang 2011.

Hamid, M. Abdul, dkk. Pembelajaran Bahasa Arab, Malang: UIN-Maliki Press 2008. 